\title{
Ceremonial y protocolo a través del cine: una propuesta metodológica para la innovación docente
}

\section{Ceremonial and protocol through cinema: a methodological proposal for teaching innovation}

\author{
Marta Pulido Polo ${ }^{1}$ \\ Universidad de Sevilla \\ labicicletade@yahoo.com
}

Recepción: 23/09/2015 Revisión: 24/10/2015 Aceptación: 27/10/2015 Publicación: 01/12/2015 http:// (página web de inclusión del artículo)

\section{Resumen}

Desde una perspectiva relacionista, la organización de actos no solo ofrece un escenario privilegiado para la gestión directa de los vínculos que se establecen entre una organización y los públicos de su universo, sino que, además, permite a través de las normas sintácticas del ceremonial y el protocolo, la articulación y posterior transmisión de determinados mensajes corporativos que generan, consecuencialmente, elevados niveles de imagen y reputación organizacional. Desde estos postulados, el cine se erige como una herramienta pedagógica eficaz para la innovación docente del ceremonial y el protocolo capaz de aunar lo formativo y lo lúdico. A través de una revisión teórica fundamentada en el uso de fuentes secundarias, este trabajo tiene como objetivo realizar una propuesta metodológica para la innovación docente del ceremonial y el protocolo que refleje los beneficios derivados de las experiencias previas resultantes del uso del cine en el aula universitaria.

Palabras clave: Cine, Ceremonial, Protocolo, Organización de actos, Innovación docente

\footnotetext{
${ }^{1}$ Doctora en Comunicación y Licenciada en Publicidad y Relaciones Públicas por la Universidad de Sevilla. Profesora del Departamento de Marketing y Comunicación de la Universidad de Cádiz. Profesora del Departamento de Comunicación Audiovisual de la Universidad de Sevilla. Profesora de EUSA, Centro adscrito a la Universidad de Sevilla. Directora de la Consultora La Bicicleta de Design \& Communication. Presidenta de Honor de la Asociación Universitaria de Relaciones Públicas y Protocolo de Andalucía (ARPPA).
} 


\begin{abstract}
From a relacionist perspective, the organization of events not only offers a privileged setting for the direct management of the links established between an organization and their publics, but also allows through syntactic rules of ceremonial and protocol, the joint and subsequent transfer of certain corporate messages that generate high levels of organizational image and reputation. From these postulates, cinema stands as an effective pedagogical tool for ceremonial and protocol teaching innovation. Through a theoretical review based on the use of secondary sources, this paper aims to make a methodological proposal for ceremonial and protocol innovation teaching in order to reflect previous experiences resulting from the use of cinema in the university classroom.
\end{abstract}

Keywords: Cinema, Ceremonial, Protocol, Organizing events, Teaching innovation.

\title{
Sumario
}

1. El ceremonial y el protocolo: una perspectiva relacionista.

2. El cine como herramienta docente.

3. La organización de actos como técnica de relaciones públicas en tres películas.

4. Los orígenes y la historia del ceremonial y el protocolo en dos películas.

5. Conclusiones: una propuesta metodológica para la innovación docente del ceremonial y protocolo a través del cine.

6. Bibliografía.

\section{Summary}

1. Ceremonial and protocol: a relacionist perspective.

2. Cinema as a pedagogical tool.

3. The organization of events as a public relations technique in three films.

4. The origins and history of ceremonial and protocol in two films.

5. Conclusions: a methodological proposal for ceremonial and protocol teaching innovation through cinema.

6. Bibliography.

\section{EL CEREMONIAL Y EL PROTOCOLO: UNA PERSPECTIVA RELACIONISTA.}

Las relaciones públicas describen un proceso directivo que se encarga de gestionar las relaciones que las organizaciones establecen con los diferentes públicos de su entorno. A través del empleo de técnicas específicas de gestión de la comunicación organizacional este 
proceso tiene como finalidad perseguir la confluencia de intereses entre la entidad emisora y los públicos de su entorno, generando un caldo de cultivo que permite a la organización desarrollar sus objetivos y metas corporativas, generando además, como consecuencia, una imagen y reputación favorables.

Un repaso por las principales definiciones de relaciones públicas evidencia la existencia de dos corrientes principales: aquellas definiciones que centran el interés de la disciplina en su carácter dialógico y bidireccional (Bernays, 1998 y Seitel, 2002) y aquellas definiciones que se encargan de destacar su naturaleza comunicacional (Long y Hazelton, en Wilcox, Cameron y Xifra, 2009). Frente a estas corrientes, Ledingham (2006) propone un nuevo enfoque para el estudio de las relaciones públicas desde aquellos postulados que estudian la emergencia de la perspectiva relacional frente a la focalización en las prácticas de comunicación para la gestión de las relaciones de la organización sus públicos. Esta perspectiva relacional de las relaciones públicas propone una reconceptualización de la disciplina sustentada en que la búsqueda del equilibrio entre el interés de las organizaciones y el de sus públicos se consigue a través de la gestión de las relaciones organización-público. Es decir, la función esencial de las relaciones públicas es gestionar, ya no un sistema de comunicación bidireccional, sino todo el entramado de relaciones que supone el ecosistema en el que tanto la organización como sus públicos se ven envueltos.

Desde esta perspectiva relacionista, la organización de actos y eventos, permite un contacto directo entre la organización y sus stakeholders, favoreciendo un proceso dialógico organización-público sin intermediarios, orientado a gestionar la estructura relacional sobre la que se construye su entorno, ya que ambos comparten las mismas coordenadas espaciotemporales. Integrado en este paradigma, el estudio de la organización de actos como técnica de relaciones públicas ofrece un valor referencial frente al resto de técnicas de gestión de comunicación organizacional, ya que posibilita a las entidades promotoras de los actos y eventos la gestión directa de las relaciones con su mapa de públicos.

Observar la organización de actos y eventos como técnica de gestión de las relaciones implica realizar una breve aproximación al concepto de vínculo. El concepto de vínculo es una de las piedras angulares de la teoría situacional de los públicos y se sustenta en la concepción sistémica del proceso de las relaciones públicas en las organizaciones. La 
perspectiva sistémica de las relaciones públicas describe una relación consecuencial entre el sistema organización y el resto de sistemas de su entorno. Cuando el sistema organización tiene consecuencias sobre otros sistemas externos (públicos) ambos sistemas se interpenetran, generando un sistema de consecuencias recíprocas organización-públicos. Analizar el sistema de relaciones que una organización establece con otros sistemas de su entorno, permite identificar el mapa de públicos de la organización. Aquel sector del entorno o público (sistema interpenetrado) puede reaccionar generando conflicto con la organización. Para resolver el conflicto, la organización debe negociar y llegar a un punto de encuentro (compromiso) con el sistema y, en la mayoría de casos, cambiar su conducta. Esto es, el proceso de dirección y gestión de relaciones públicas, al que se hacía mención antes, cuyos responsables ayudan a la organización a hacer planes afrontar las interrupciones de su equilibrio con el entorno. En este proceso, el concepto de vínculos se utiliza para determinar los sistemas interpenetrantes que suelen trastornar el equilibrio de la organización. Los vínculos existentes entre una organización y sus públicos pueden ser posibilitadores, funcionales, normativos y difusos. Los vínculos posibilitadores son aquellos que las organizaciones mantienen con determinados grupos sociales que proporcionan la autoridad y controlan los recursos que hacen posible la existencia de la organización. Los funcionales son los vínculos que se establecen con las organizaciones que proporcionan inputs y toman outputs de nuestra entidad. De esta forma, los vínculos funcionales pueden ser de input (relaciones con los empleados, sindicatos y proveedores de materias primas) o de output (con organizaciones que utilicen los productos de la organización). Los vínculos normativos son los que se establecen con aquellas organizaciones que se enfrentan a problemas semejantes o comparten los mismos valores que la nuestra. Finalmente, los vínculos difusos son aquellos que no pueden ser claramente identificados por ser miembros de organizaciones formales. Gestionar estos vínculos permite comprender por qué las organizaciones tienen determinados programas de relaciones públicas y planificar qué programas son los más adecuados para una organización. Aplicado al ámbito de la organización de actos y eventos, la importancia de los vínculos se eleva dada la naturaleza directa de la comunicación organización-públicos. En este sentido, la organización de un evento debe contemplarse como una herramienta de gestión eficaz de la comunicación, en la que el listado de invitados, lejos de ser un elemento trivial, se erige como uno de los elementos más relevantes del proceso de gestión, ya que debe obedecer a un estricto 
análisis de los vínculos que la organización emisora del evento mantiene con su entorno. Solo de esta forma, la organización de actos y eventos, se erige como una técnica eficaz de relaciones con los públicos para establecer una comunicación dialógica con los públicos de interés y poder generar como consecuencia los mensajes corporativos adecuados a los destinatarios pertinentes (Grunig y Hunt, 2000).

Para Otero (2011: 69) estos planteamientos resultan especialmente adecuados cuando se analizan los eventos como acciones de relaciones públicas diseñados para crear y/o mejorar sus relaciones con alguno de sus públicos, por lo que podríamos hablar en cierto modo de un sistema de comunicación selectiva activada en función del tipo de vínculos existentes entre las diferentes partes de su universo. En la mayor parte de las ocasiones, la gestión de las consecuencias que la organización tiene sobre sus públicos y viceversa se manifiesta en la forma de imagen o reputación (positivas) para la organización sujeto promotor del programa de relaciones públicas en el que se enmarca la organización de actos como técnica.

A su vez la imagen o reputación corporativas se traducen en una legitimación de la organización ante los públicos de su entorno (sistemas externos a los que interpenetra en una relación consecuencial o conflictual) que favorece el clima de entendimiento mutuo objetivo final de las relaciones públicas (ver gráfico).

En este contexto, podemos concluir que la organización de actos como técnica de relaciones públicas no solo ofrece un escenario privilegiado para la gestión directa de los vínculos que se establecen entre la organización emisora y los públicos de su universo, sino que además permite, a través de las normas sintácticas del ceremonial y el protocolo, la articulación y posterior transmisión de determinados mensajes corporativos, orientados a gestionar la , relación entre la organización y sus públicos, que generan consecuencialmente elevados niveles de imagen y reputación organizacional. 
Gráfico: La organización de eventos como estrategia de gestión de los vínculos organización-públicos.
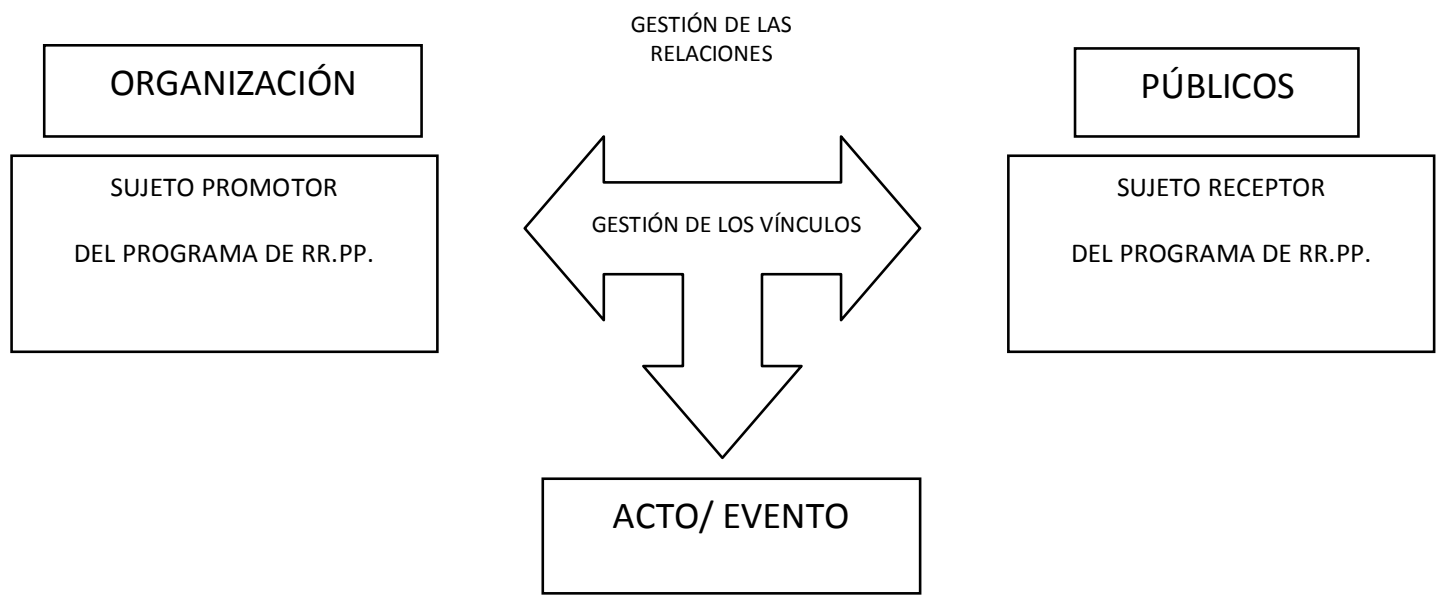

TÉCNICA ESPECÍFICA DE RR.PP.
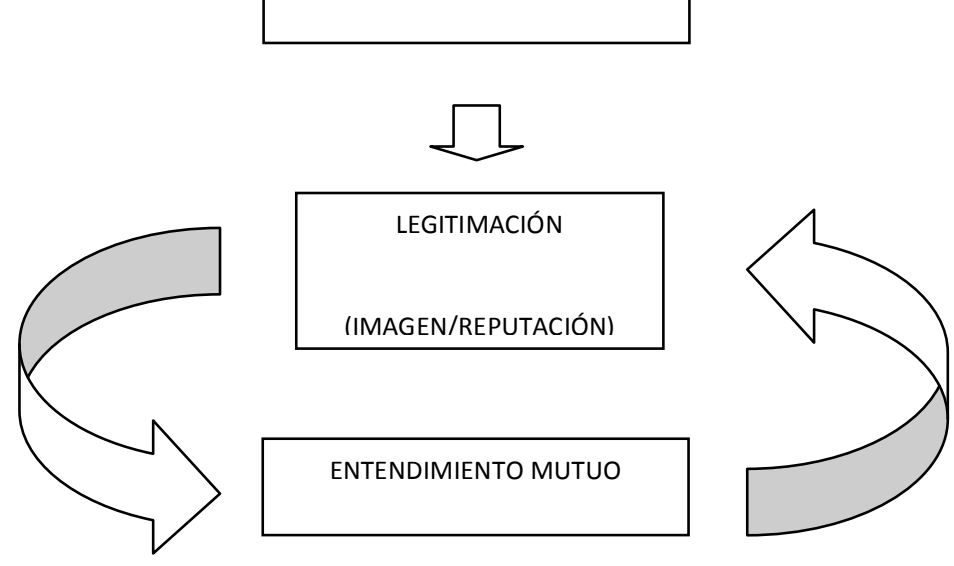

Fuente: elaboración propia.

\section{EL CINE COMO HERRAMIENTA DOCENTE}

En los últimos años, la difusión masiva de la televisión y las nuevas tecnologías, ha supuesto el paso hacia una cultura fundamentalmente audiovisual que ha convertido el cine en un instrumento educativo capaz de superar la lectura y la escritura como tradicionales vehículos información en el aula (Pereira Domínguez, 2005). Como afirma Marcos Recio (2001), durante muchos años el único material con el que el profesor ha podido trabajar con sus alumnos ha sido el papel a través del libro de texto. Sin embargo, en la actualidad la imagen, 
tratada técnicamente para el cine y la televisión, se ha convertido en el elemento educativo por excelencia.

En este sentido, lejos del mero uso documental, el cine se erige como una verdadera estrategia interdisciplinar que coadyuva al proceso de enseñanza-aprendizaje, facilitando por un lado a los estudiantes la comprensión y adquisición de conceptos abstractos y, por el otro, proporcionando al profesor una herramienta que aúna lo lúdico y lo creativo, dando como resultado una experiencia significativa, tangible y experimental (Martínez Salanova, 2002).

Partiendo de los postulados de García Amilburu (2010), si entendemos la educación en su sentido más amplio y genuino, como vehículo para ayudar a otras personas al conocimiento de sus dimensiones emocional, social y moral (sin limitarse al mero conocimiento teórico) el empleo de películas puede considerarse como un instrumento pedagógico eficaz orientado a la formación integral del individuo, capaz de fomentar el espíritu crítico y la capacidad de diálogo.

En palabras de Beltrán Llavador:

El cine y la educación, la educación y el cine, (...) pueden erigirse en instrumentos poderosos de persuasión y de propaganda, o en mera evasión, pero también constituyen recursos valiosos para "el viaje de la esperanza", iluminándonos, dándonos que pensar, y posibilitando que desplacemos nuestros propios puntos de vista para adoptar el punto de vista de los otros, expandiendo nuestra autonomía (2006:90).

En este contexto, podemos afirmar entonces que el cine se erige como una herramienta eficaz para la docencia universitaria del ceremonial y el protocolo, atendiendo a una perspectiva relacional de la organización de actos y eventos. Desde esta perspectiva a continuación se sugieren algunas de las películas más relevantes atendiendo a los aspectos más destacables orientados a la docencia del ceremonial y el protocolo en el ámbito universitario y académico. 


\section{LA ORGANIZACIÓN DE ACTOS COMO TÉCNICA DE RELACIONES PÚBLICAS EN TRES PELÍCULAS.}

\subsection{La guerra de Charlie Wilson.}

\subsubsection{Ficha técnica de la película.}

Título original: Charlie's Wilson war

Dirección: Mike Nichols

País: Estados Unidos

Año: 2007

Duración: 97 minutos

Género: Drama, Política

Reparto: Tom Hanks, Julia Roberts, Philip Seymour Hoffman, Amy Adams, Ned Beatty, Emily Blunt, Om Puri, Brian Markinson, Rachel Nichols

Web oficial: http://www.charliewilsonswar.net

Productora: Universal Pictures

Sinopsis: La guerra de Charlie Wilson es una película basada en hechos reales que narra cómo un congresista de los Estados Unidos, Charlie Wilson, gestiona en los años 80 una guerra encubierta de Estados Unidos con la antigua Unión Soviética a través de una operación clandestina armada de ayuda a Afganistán, bombardeada sistemáticamente por el ejército ruso, en colaboración con Pakistán, Egipto e Israel.

\subsubsection{La organización de actos en La guerra de Charlie Wilson.}

No tratando directamente sobre relaciones públicas, la película es un elemento referencial a tener en cuenta en la docencia de las relaciones públicas ya que, no solo refleja los entresijos de las decisiones que se toman en el Congreso de los Estados Unidos y permite acercar al alumno al fenómeno del lobby y la influencia en la opinión pública, sino que también permite observar un magnífico abanico de técnicas de relaciones públicas como el famtrip, la relación con los medios de comunicación, la gestión de crisis y, por supuesto, la organización de actos y el fundraising. 
Desde la perspectiva de la organización de actos como técnica específica de relaciones públicas es posible estudiar con el alumno tres aspectos concretos: el protocolo institucional, el fundraising y la importancia de la diplomacia en el protocolo internacional.

\subsection{2. a. Protocolo institucional.}

La película comienza y acaba con un acto institucional a través del cual el Congreso de los Estados Unidos homenajea al congresista Charlie Wilson y le impone la medalla de honor de los servicios clandestinos por su papel en la lucha contra la Unión Soviética en la invasión a Afganistán. El acto escenifica formalmente a través de una ceremonia la necesidad de legitimar al artífice de la guerra encubierta contra la Unión Soviética no ante la opinión pública (se trataba de una operación encubierta llevada a cabo por los servicios clandestinos) pero si ante los públicos del entorno cercano a Charlie Wilson.

Esta secuencia, permite evidenciar la necesidad de identificar al mapa de públicos destinatario del mensaje corporativo de reconocimiento del mérito y de legitimidad que se lanza a través de la ceremonia recreada y cuyo doble emisor es institucional: El Congreso de los Estados Unidos y la CIA. Puede observarse, por tanto, cómo a través del empleo de la organización de una ceremonia laudatoria, es posible identificar la presencia de los tres elementos tradicionales de las relaciones públicas identificados por Xifra (2003): emisor organizacional, mensaje informativo-persuasivo de legitimación y públicos.

Como elementos anexos, también destaca el uso de la decoración corporativa institucional, típica de la cultura norteamericana, pero perfectamente extrapolable a la organización de actos corporativos al uso, sustentada en el empleo de los colores institucionales de la bandera y los símbolos nacionales norteamericanos. De hecho, este aspecto de la película es comparable con los actos organizados por entidades comerciales como Porcelanosa o instituciones como la Fundación Princesa de Asturias, que rentabilizan el uso de emblemas, símbolos y colores organizacionales en la celebración de sus actos en pos de reforzar el mensaje corporativo que es origen y fin del acto celebrado.

\subsection{2. b. Fundraising.}

La guerra de Charlie Wilson permite también introducir al alumno en el concepto de fundraising como técnica específica orientada a gestionar las relaciones con los públicos 
organizacionales. Literalmente, el término anglosajón fundraising hace referencia a la captación de fondos, si bien en la literatura relacionista se utiliza en muchos textos para denominar a aquellos actos organizados con la finalidad de recaudar dinero con fines sociales, comunitarios y/o benéficos.

Desde esta perspectiva, es una técnica de relaciones públicas que suele enmarcarse en políticas corporativas ligadas al ámbito de la responsabilidad social por cuanto no suelen utilizarse para la captación de fondos propios sino para colaborar a la satisfacción de alguna necesidad social ajena a la propia corporación. Tal y como puede observarse en la película, la amiga de Charlie Wilson, la tercera mujer más rica de Texas, consigue atraer la atención del congresista sobre el problema afgano invitándolo a una fiesta que organiza en su casa para visionar un filme que tiene como objetivo concienciar a los ricos filántropos invitados asistentes sobre la necesidad de recaudar dinero para ayudar al pueblo afgano a reaccionar contra los ataque soviéticos.

Llegados a este punto, conviene aclarar que, a diferencia de otros países, la legislación norteamericana permite que las organizaciones políticas se autofinancien a través de la captación de fondos de sus simpatizantes y/o seguidores, cuestión esta que es perfectamente observable en la película cuando Charlie Wilson celebra con sus seguidores su reelección como congresista.

\subsection{2. c. Protocolo internacional y diplomacia.}

En este proceso de conversión a la causa afgana, a Charlie Wilson le organizan una reunión con el Presidente de Pakistán en la que tanto el Presidente Pakistaní como su equipo asesor en cuestiones militares tratan de conseguir cierto grado de compromiso por parte de Estados Unidos para que les proporcionen armas y poder, de este modo, ayudar a Afganistán contra los ataques soviéticos.

Además de las cuestiones protocolarias clásicas en este tipo de encuentros (como la adecuación en la vestimenta femenina occidental a la oriental durante la visita), la importancia que el Presidente le proporciona mediáticamente al encuentro (no puede faltar la amable foto protocolaria de rigor para transmitir a la opinión pública los altos niveles de relaciones internacionales con líderes norteamericanos) o las pautas a seguir en la recepción 
de una visita de cortesía en las instalaciones propias, la película permite evidenciar la importancia de asesorarse sobre las costumbres de los países que se visitan para no herir sensibilidades y que los encuentros bi y multilaterales se desarrollen sin incidencias, generando el mejor de los escenarios posibles para una negociación fructífera. Este aspecto concreto se aprecia perfectamente al comienzo de la secuencia que escenifica el desarrollo del encuentro entre Charlie Wilson, el Presidente pakistaní y su comité asesor. Cuando el Presidente le indica al congresista norteamericano que tome asiento, le ofrece por cortesía algo de beber. En ese momento Charlie Wilson, obviando completamente las costumbres habidas en un país musulmán, pide un whisky y, ante la sorpresa de la delegación pakistaní, es el Presidente quien se ve obligado a recordarle que en la residencia oficial del Presidente de Pakistán no se sirve alcohol.

\subsection{Aladdín.}

3.2.1. Ficha técnica de la película.

Título original: Aladdin

Dirección: Ron Clements, John Musker

País: Estados Unidos

Año: 1992

Fecha de estreno: 18/11/1993

Duración: 90 minutos

Género: Romance, Musical, Familiar, Animación, Aventuras, Fantástico

Reparto original: Scott Weinger, Robin Williams, Linda Larkin, Jonathan Freeman, Frank Welker, Gilbert Gottfried, Douglas Seale, Bruce Adler, Brad Kane, Lea Salonga

\section{Productora: Walt Disney Pictures, Walt Disney Feature Animation}

Sinopsis: La película está basada en uno de los cuentos de origen sirio de Las mil y una noches, Aladino y la lámpara maravillosa, y narra las aventuras de un hábil joven que subsiste robando y sueña con casarse con la hija del Sultán. La suerte se pone a su favor cuando recupera una lámpara mágica a través de la cual un genio le concederá tres deseos. 


\subsubsection{La perspectiva relacionista de la organización de actos en Aladdín.}

La utilidad de la película, desde la perspectiva relacionista de la organización de actos y eventos, se centra en la secuencia que describe la entrada en Agrabah del Gran Príncipe Alí. Esta secuencia permite evidenciar dos aspectos relevantes de la organización de actos: la identificación de los públicos de interés y la vehiculación de un mensaje de legitimidad adaptado a las necesidades y expectativas de cada público.

\subsection{2. a. La identificación de los públicos de interés.}

La secuencia señalada narra el gran evento de presentación que el relacionista público de Aladín (el genio de la lámpara) organiza para rentabilizar públicamente la entrada del nuevo Príncipe Alí en la ciudad de su amada, Agrabah. Amenizada con una de las canciones más populares de la película, se va mostrando cómo el genio ha preseleccionado los grandes públicos de interés ante los que Aladín debe legitimarse si quieres posicionarse como un buen candidato a futuro esposo de la princesa. De este modo realiza acciones concretas, verbalizadas a lo largo de la canción, dirigidas al mapa estratégico de públicos de Aladín: el ejército del Sultán, la opinión pública masculina, la opinión pública femenina, los medios de comunicación, los niños, los ancianos, los pobres y el propio Sultán.

La identificación de los públicos clave es uno de los pasos más relevantes de la fase de planificación identificada en el método IAEC (Xifra, 2005) para la planificación estratégica de las relaciones públicas organizacionales y debe basarse en la identificación adecuada de los públicos clave de interés para la transmisión de los mensajes corporativos preestablecidos enmarcados en los objetivos, metas y política organizacionales.

3.2.2. b. La vehiculación de un mensaje de legitimidad adaptado a las necesidades y expectativas de cada público identificado.

Si es importante identificar el mapa de públicos en el proceso de planificación estratégica, igualmente relevante es saber vehicular adecuadamente los mensajes corporativos a cada uno de los públicos seleccionados. Bajo el mensaje organizacional global orientado a la búsqueda de notoriedad y legitimación como buen candidato a esposo de la princesa y futuro Sultán, en el fragmento reseñado, se evidencian las virtudes del joven casadero en función de los intereses y expectativas de los públicos. De este modo, a las señoras se les 
ensalzan las virtudes masculinas de Aladín, a los militares se les obliga a rendirle sumisión, a los pobres les reparte monedas de oro, y así sucesivamente hasta recrear ante los ojos del Sultán al yerno perfecto.

La coordinación de dichos mensajes particulares orientados concretamente a cada uno de los públicos identificados conforma el mensaje global organizacional que persigue Aladín a través de la organización de actos, concebida claramente como una técnica de relaciones con los públicos.

\subsection{Vatel.}

\subsubsection{Ficha técnica de la película.}

Título original: Vatel

Dirección: Roland Joffé

País: Francia, El Reino Unido, Bélgica

Año: 2000

Duración: 103 minutos

Género: Drama, Romance, Biográfico

Reparto: Gérard Depardieu, Uma Thurman, Tim Roth, Timothy Spall, Julian Glover, Julian Sands, Murray Lachlan Young, Hywel Bennett, Richard Griffiths, Arielle Dombasle

Productora: Gaumont, TF1 Films Production, Timothy Burrill Productions, Canal+, Légende Entreprises, Nomad Films

Sinopsis: En 1671, el Príncipe de Condé, caído en desgracia con Luis XIV por haber participado en una rebelión nobiliaria contra la corona y al borde de la ruina, invita al Rey y a toda su corte a la reinauguración de su palacio en Chantilly. Estratégicamente, utiliza esta ocasión para ordenar a su maestro de ceremonias, Vatel, organizar una opulenta fiesta que tendría lugar durante tres días y tres noches para seducir al rey y escenificar públicamente su reconciliación con el Rey Sol ante toda su corte de más de tres mil invitados. La película se centra en narrar todo cuanto acontece a lo largo de estos tres días, ajustándose con bastante minuciosidad a la realidad de los acontecimientos desde el romance con la favorita del Rey hasta el dramático suicidio de su protagonista. 


\subsubsection{El maestro de ceremonia como antecedente del Jefe de protocolo.}

François Vatel, nacido como Fritz Karl Watel (París, 1631 - Chantilly, 1671), comienza su carrera como aprendiz de repostero y pronto entra a trabajar al servicio de Nicolás Fouquet, Ministro de Finanzas de Luis XIV. Cuando Fouquet es condenado y arrestado por malversación, Vatel entra al servicio del Príncipe de Condé (Luis II) en Chantilly. En la película resulta evidente cómo la organización de los fastos de recepción a Luis XIV se utilizan como una técnica orientada a gestionar las relaciones generando así un clima favorable para que el Príncipe pudiera disfrutar de nuevo del favor del rey y solventar así su ruina económica. No obstante, además de este aspecto concreto, desde una perspectiva docente, la película permite estudiar, entre otras cuestiones, aspectos concretos como la utilidad histórica de los banquetes para generar afinidades, la evolución de las costumbres y pautas alimenticias o del virtuosismo que debe regir la profesión protocolar. En primer lugar, los banquetes han sido el reflejo de situaciones sociopolíticas y económicas concretas de cada época y se han venido organizando a lo largo de toda la historia bien para celebrar una victoria, bien para sellar un acuerdo, bien para negociar con determinados líderes opositores. Del mismo modo, frente a la desmesura de los banquetes medievales y del primer Renacimiento serán los italianos, y en concreto los florentinos, quienes impongan al resto de cortes europeas "el buen gusto" en las costumbres, los modos de vestir o las pautas alimenticias. Finalmente, la película revela un maestro de ceremonias culto, conocedor de Descartes, y con elevado gusto por el detalle y lo exquisito en la creación de experiencias fascinantes y sorprendentes acorde los ilustres invitados que tiene como públicos organizacionales (Vázquez Sallés, 2006 y Calero Ruiz, 2011).

Finalmente, el visionado de la película permite reflexionar sobre la figura del maestro de ceremonias como antecedente del actual Jefe de Protocolo, dado el objetivo común que comparten en diferentes ámbitos espaciotemporales: recrear a través de los actos organizados el clima adecuado para que se cumpla el objetivo organizacional con el que se organiza y se transmitan los valores institucionales y/o empresariales necesariamente predeterminados. 


\section{LOS ORÍGENES Y LA HISTORIA DEL CEREMONIAL Y EL PROTOCOLO EN DOS PELÍCULAS.}

\subsection{Avatar.}

\subsubsection{Ficha técnica de la película.}

Título original: Avatar

Dirección: James Cameron

País: Estados Unidos

Año: 2009

Fecha de estreno: 18/12/2009

Duración: 150 min

Género: Thriller, Aventuras, Acción, Ciencia ficción

Reparto: Michelle Rodriguez, Zoe Saldana, Sam Worthington, Giovanni Ribisi, Sigourney Weaver, Laz Alonso, Wes Studi, Stephen Lang, Joel Moore, CCH Pounder

Productora: Twentieth Century-Fox Film Corporation, Lightstorm Entertainment, Giant Studios

Sinopsis: La película, ambientada en el año 2154 describe cómo una empresa envía una expedición de militares y científicos a Pandora para estudiar una cultura alienígena nativa, los Na'vi, con el objetivo de extraer grandes cantidades de un nuevo mineral extremadamente valioso. Uno de los militares enviados es Jake Sully, un joven paralítico cuya vida cambia radicalmente cuando conoce a Neytiri, la joven princesa Na'vi.

\subsubsection{Avatar y el origen del ceremonial a través del rito.}

El origen del ceremonial y el protocolo se sitúa en el rito como elemento vertebrador de las primeras comunidades humanas. De hecho, mucho antes de la aparición de la escritura existen representaciones de carácter ceremonial orientadas al culto de divinidades o al posicionamiento hegemónico de determinados líderes, ya se trate de objetos y figuras simbólicas o realistas en los primeros santuarios neolíticos a la Diosa Madre en Catal Huyuk, Turquía (6700-5700 A.C.); templos sumerios del calcolítico mesopotámico en la antigua ciudad de Eridu (5000-4750) o esquemas heráldicos y fiestas religiosas en la glíptica sumeria (3500-2800 a.C.) (Otero, 2000: 38). 
Estas manifestaciones primigenias de origen ritual se fueron consolidando con el paso del tiempo hasta derivar en las primeras representaciones ceremoniales y protocolarias, sentando así las bases de los principios rectores actuales de la organización de actos y sus técnicas de ordenación.

En este sentido, las primeras manifestaciones de vida humana en comunidad fueron desarrollando los espacios y los tiempos necesarios para legitimar al líder político y al líder espiritual, bien por separados, bien concentrados en la misma figura. De esta forma, la película Avatar nos permite recrear, desde la ficción, cómo fueron las primeras comunidades humanas y, si analizamos la vida tribal de los Na'vi, podemos observar cómo el líder político y la líder espiritual, conforman un matrimonio perfecto (padre y madre de la Princesa Neytiri) que, aunando ambos poderes, se legitiman ante el resto de la tribu como individuos especiales de los que depende la supervivencia de la especie: la seguridad políticomilitar y la espiritual. Cada uno con sus funciones propias y su espacio ritual especial y destacado del resto. De este modo, Naytiri está llamada a ser la siguiente líder espiritual y su futuro marido, el político.

\subsection{Juana la loca.}

4.2.1. Ficha técnica de la película.

Título original: Juana la loca

Dirección: Vicente Aranda

País: España, Italia, Portugal

Año: 2001

Fecha de estreno: 28/09/2001

Duración: 115 minutos

Género: Drama, Romance, Histórico, Biográfico

Reparto: Pilar López de Ayala, Daniele Liotti, Rosana Pastor, Giuliano Gemma, Roberto Álvarez, Eloy Azorín, Guillermo Toledo, Susi Sánchez, Chema de Miguel, Andrés Lima

Productora: Eurimages, Canal+ España, Take 2000, Sogepaq, Enrique Cerezo Producciones Cinematográficas S.A., Pedro Costa Producciones Cinematográficas S.A., Production Group 
Sinopsis: La película escenifica la partida de la infanta Juana de Castilla a la corte de Bruselas para sus nupcias con Felipe el Hermoso. Aunque en sus comienzos, el deseo entre ambos cónyuges marca la relación, pronto los problemas políticos y conyugales harán mella en la infanta que pasará a la historia como Juana la Loca.

\subsubsection{Los Reyes Católicos y la historia del ceremonial en España.}

La película permite tratar dos temas relevantes desde la perspectiva histórica del ceremonial y el protocolo: los reyes católicos (secuencia inicial de la película en la que la Reina Isabel instruye a su hija en lo que debe ser su matrimonio) y el nacimiento de las primeras reglas ceremoniales y la conocida como etiqueta hispana (escena que recrea cómo Juana da a luz al que será el Emperador Carlos I de España y V de Alemania en el pleno de una celebración).

Los Reyes Católicos imprimen a la monarquía hispana un carácter cortesano y palatino desconocidos hasta el momento, emprendiendo una ambiciosa política de imagen pública basada especialmente en las bellas artes y la etiqueta. De hecho son los responsables de implantar un primer ceremonial concebido como un sistema de reglas que buscaba rodear a los soberanos de grandeza, evidenciando el distanciamiento con el resto de la corte (Otero, 2000: 67-70).

Del matrimonio de su hija, la infanta Juana de Castilla, Juana la Loca, con Felipe el Hermoso, nacerá el emperador Carlos I de España y V Alemania, responsable último de introducir las costumbres borgoñonas, conocido posteriormente como el ceremonial borgoñón o la etiqueta hispana, en la corte española. El emperador impuso a su hijo el Príncipe D. Felipe (Felipe II) el nuevo ceremonial en su viaje a Flandes (1548) para ser proclamado heredero de los Países Bajos, y en esta fecha el Duque de Alba, su mayordomo mayor, recibió la orden de implantar "el uso borgoñón" en la casa del príncipe don Felipe. No es desdeñable la intencionalidad política de este hecho puesto que resulta evidente pensar que los Países Bajos admitirían mejor al nuevo Príncipe si éste se regía por las viejas costumbres borgoñonas. Desde entonces, la Corona española ha utilizado este ceremonial borgoñón, mezclado con elementos de Castilla y Aragón, y en adelante, cada soberano irá introduciendo los cambios convenientes para adaptar su reinado a los nuevos tiempos (Otero, 2000: 70-73). 


\section{CONCLUSIONES: UNA PROPUESTA METODOLÓGICA PARA LA INNOVACIÓN DOCENTE DEL CEREMONIAL Y PROTOCOLO A TRAVÉS DEL CINE.}

El cine se ha erigido en los últimos tiempos como una herramienta pedagógica de innovación docente eficaz en el ámbito educativo en general (Pereira Domínguez, 2005) y en el ámbito universitario en particular (Otero Alvarado, 1998 y Jiménez y Elías, 2012).

Desde esta perspectiva y atendiendo a los postulados que propugnan el estudio de la organización de actos desde la teoría relacional de las relaciones públicas, el denominado cine comercial de las últimas dos décadas ofrece al docente una serie de títulos, ni mucho menos agotados en este texto, que pueden ser utilizados para amenizar y rentabilizar la docencia de aspectos concretos relacionados con la teoría y la práctica del ceremonial y el protocolo, desde la identificación estratégica del mapa de públicos organizacionales, hasta el origen de las actuales técnicas de precedencia oficial.

En este sentido, tomando como punto de partida las reflexiones de García Amilburu (2010: 28), una propuesta metodológica eficaz para la innovación docente del ceremonial y el protocolo en el ámbito universitario exige que la película:

- Sea capaz de exponer un tema relacionado con la organización de actos, el ceremonial y el protocolo, reforzando el aprendizaje de unos contenidos concretos.

- Permita ejercer hábilmente la capacidad crítica del alumno.

- Fomente y ponga en práctica la capacidad de diálogo mediante la elaboración y defensa razonada de una opinión propia, prestando atención y respetando las opiniones de los demás.

- Sea seleccionada obedeciendo al menos a alguna de las siguientes motivaciones fundamentales:

- Trata sobre un tema relacionado con la asignatura que "conecta" con los estudiantes y les permite reflexionar sobre determinadas cuestiones académicas o profesionales de la disciplina objeto de estudio. 
- llustrar adecuadamente algún contenido teórico o práctico relacionado con el programa de la asignatura que imparte.

- Representa diferentes roles o conflictos éticos profesionales relacionados con la práctica profesional de la disciplina trabajada.

\section{BIBLIOGRAFÍA.}

AMAR, V. 2009. "El cine en la encrucijada de la educación y el conocimiento". Enl@ce. Revista Venezolana de Información, Tecnología y Conocimiento. Vol. 6. № 2: 131-140.

AMEIJEIRAS, S. y MORÓN, J. A. 1998. "Educación para la salud a través del cine". Comunicar. № 11: 123-128.

ARCEO VACAS, J. L. 2004. Las relaciones públicas en España. Mc Graw Hill. Madrid.

BELTRÁN LLAVADOR, J. 2006. "Sobre cine, sociedad y educación. Cómo hacer cosas con imágenes". Educación y Juventud: problemas actuales y abordajes teóricos Revista de Ciencias Sociales. № 23: 88-99.

BERNAYS, E. L. 1998. Cristalizando la opinión pública. Editorial Gestión 2000. Barcelona.

CALERO RUIZ, C. 2011. "Vatel y otros arquitectos de sueños efímeros. Banquetes, sentidos y triunfo en las cortes europeas de la época moderna". Revista Latente. № 9: 45-58

CASTILLO, A. 2010. Introducción a las relaciones públicas. Ed. IIRP. Málaga.

COMESAÑA, P. 2012. "Las Relaciones Públicas como estrategia de comunicación en los eventos cinematográficos: los Premios Goya". Revista Internacional de Relaciones Públicas. Vol. II. №. 16: 113-130.

CUTLIP, S. M. y CENTER, A. H. 2001. Relaciones públicas eficaces. Editorial Gestión 2000. Barcelona.

DE LA TORRE, S. 1996. Cine formativo una estrategia innovadora en la enseñanza. Editorial Octaedro. Barcelona. 
GARCÍA AMILBURU, M. 2010. “Cine y educación: la integridad del docente en Emperor's club". Edetania. № 38: 27-40.

GÓMEZ DE BENITO, J. L. 1996. “Psicología, cine y educación”. Comunicar. № 7: 129-134.

GRUNIG, J. E. y HUNT, T. 2000. Dirección de relaciones públicas. Editorial Gestión 2000. Barcelona.

GRUPO EMBOLIC. 1998. “Cómo enseñar filosofía con la ayuda del cine”. Comunicar. № 11: 76-82.

JIMÉNEZ MARÍN, G. y ELÍAS ZAMBRANO, R. 2012. "El cine como instrumento para la formación en la universidad. Experiencias en las universidades de Cádiz y de Sevilla". Aularia: Revista Digital de Comunicación. Vol. 1. № 2: 163-169.

LEDINGHAM, J. A. 2006. "Relationship management: a general theory of public relations" en BOTAN, C. y HAZLETON, V. (coord.). Public Relations Theory II. pp 534- 568. Lawrence Earlbaum Associates, Inc. Mahwah (New Jersey).

LOZANO BOTACHE, J. P. 2012. “Cine e interdisciplinariedad en la educación”. Libro de actas. I Congreso Virtual Internacional sobre Innovación Pedagógica y Praxis Educativa.

MARCOS RAMOS, M. 2010. “Alfabetización mediática. La educación en los medios de comunicación: cine formativo y televisión educativa". Teoría de la educación: Educación y Cultura en la Sociedad de la Información. Vol. 11. № 2: 303-321.

OTERO ALVARADO, M. T. 1998. “El banquete como acción de relaciones públicas: las comidas en La edad de la inocencia" en CARRERAS LARIO, C. y CRESPO GÁMEZ, C. (coord.). Cien años de cine: la fábrica y los sueños. pp. 321-327. Ed. Universidad de Sevilla, Facultad de Ciencias de la Información. Sevilla.

OTERO ALVARADO, M. T. 2000. Teoría y estructura del ceremonial y el protocolo. Mergablum edición y comunicación. Sevilla. 
OTERO ALVARADO, M. T. 2006. "Relaciones públicas y gestión de públicos en eventos: los principios rectores del ceremonial y el protocolo". Anàlisi: Quaderns de comunicació i cultura. №. 34: 255-269.

PEREIRA DOMÍNGUEZ, M. C. 2005. "Cine y educación social”. Revista de Educación. № 338: 205-228.

REIA BAPTISTA, V. 2005. "El valor pedagógico del cine". Ámbitos. Revista Internacional de Comunicación. № 13-14: 213-229.

SÁNCHEZ GONZÁLEZ, M. D. M. 2011. Fundamentos del Ceremonial y del Protocolo. Síntesis. Madrid.

SEITEL, F. 2002. Teoría y práctica de las relaciones públicas. Prentice Hall. Madrid.

SVENSSON, V. 2013. "Relaciones entre cine, literatura y educación". Revista Pilquen. Vol. 1. № 16: 1-13.

VÁZQUEZ SALLÉS, D. 2006. “La despensa: François Vatel. El espectáculo en la mesa de Luis XIV". Clío: Revista de historia. №. 62: 98-100.

WILCOX, D. L., CAMERON, G. T. y XIFRA, J. 2009. Relaciones públicas. Estrategias y tácticas. Pearson Addison Wesley. Madrid.

XIFRA, Jordi. 2005. Planificación estratégica de relaciones públicas. Editorial Paidós. Barcelona.

XIFRA, Jordi. 2007. Técnicas de las relaciones públicas. Editorial UOC. Barcelona. 